\title{
High-Dose Chemotherapy with Stem Cell Support
}

National Cancer Institute

\section{Source}

National Cancer Institute. High-Dose Chemotherapy with Stem Cell Support. NCI

Thesaurus. Code C38722.

Treatment with chemotherapy drugs at levels that will also destroy the bone marrow, followed by infusion of stem cells to reconstitute the immune system. 